\title{
Association between Serum Iron with Serum TNF- $\alpha$, IL-6, IGF-1 and Lipids in Both Acute Myocardial Infarction and Unstable Angina Patients
}

\author{
Omyma G.Ahmed, Ramadan A. Sayed * and Osama A. Ibrahiem** \\ Departments of Physiology, Biochemistry* and Internal Medicine**, \\ Faculty of Medicine, Assiut University Hospital, Assiut, EGYPT
}

\begin{abstract}
Background: Pro-inflammatory cytokines (interleukine -6 and tumor necrotic factor$\alpha$ ) and Insulin-like growth factor-1 (IGF-1) play important roles in pathogenesis of acute myocardial infarction (AMI) and unstable angina (UA). In addition, serum iron overload or iron deficiency appears to be associated with atherosclerosis and ischemic myocardial damage. The aim of this investigation is to verify the role of inflammatory process and IGF-1 in pathophysiology of AMI and UA as well as to investigate the relationship of circulating $I L-6, T N F-\alpha$ and IGF-1 with the levels of serum iron and lipids in those patients. Methods: IL-6, TNF- $\alpha$ and IGF-1 were measured by ELISA assays in 18 patients with AMI and 18 patients with UA after their hospital admission, as well as in 6 healthy control subjects. Lipid profile was assessed by measuring the serum levels of total cholesterol, HDL-C, LDL-C and triglycerides. Serum iron was measured by atomic absorption flame emission spectrophotometer. Results: AMI patients with low serum iron showed significant higher levels of $I L-6, T N F-\alpha, L D L-C$, cholesterol level and atherogenic index and lower levels of IGF-1 and HDL-C as compared with both low serum iron UA patients and healthy controls. On the other hand, AMI patients with high serum iron revealed non-significant differences in all previous parameters except IL-6 when compared with high serum iron UA patients. There was a significant positive correlation between serum iron with the levels of IGF-1 and HDL-C, as well as a significant negative correlation with the levels of cholesterol, triglycerides, $L D L-C, T N F-\alpha$, and IL-6 in both AMI and UA patients with low serum iron. In addition, in AMI patients with high serum iron, a significant positive correlation between serum iron with IGF1 and $H D L-C$ and negative correlation with remaining parameters was evident. Conclusions: Both AMI and UA patients were associated with a pro-inflammatory state (increased TNF- $\alpha$ and IL-6), increased risky lipids (cholesterol, triglyceride, $L D L-C$, atherogenic index) and decreased cardiac protective factors, such as IGF-1 and HDL-C. These findings support the role of inflammation in both patients' population as well as the protective role of IGF-1 in ischemic heart disease. In addition, low serum iron in both AMI and UA patients was associated with more proinflammatory state and less cardiac protection than normal subjects or patients with either normal or high serum iron. However, the deleterious effects of low serum iron were more in AMI than UA patients.
\end{abstract}




\section{INTRODUCTION}

Ischemic heart disease is due to disparity between the oxgen supply and the metabolic demand of the myocardium ${ }^{(\mathbf{1})}$. Reduction in coronary blood flow is related to progressive atherosclerosis ${ }^{(2)}$.

Insulin-like growth factor I (IGFI), which is a mitogenic peptide that circulates in plasma, has endocrine effects in numerous target tissues. Most plasma IGF-I originates from the liver, its production is stimulated by growth hormone $(\mathrm{GH})$ secretion, and IGF-I mediates many of the anabolic actions of $\mathrm{GH}^{(3)}$. In addition to its anabolic properties, it has been suggested that IGF-I plays an important role in the development of cardiovascular diseases $(\mathrm{CVDs})^{(\mathbf{4 , 5})}$. Subjects with low circulating IGF-I levels are at significantly higher risk of developing CVDs ${ }^{(\mathbf{6})}$. Because IGF-I is important for tissue repair and cell proliferation, it also involved in the pathogenesis of atherosclerosis ${ }^{(4)}$.

Atherosclerosis is widely accepted as a chronic inflammatory disease initiated by different vascular and extravascular sources ${ }^{(7)}$. The inflammatory process is involved throughout the different stages of atherosclerosis. The vulnerability of an atherosclerotic plaque is related to the presence of inflammation since it plays a crucial role in disruption of the fibrous cap, which is a major pathophysiological event for the development of the acute coronary syndromes, such as acute myocardial infarction (AMI) and unstable angina (UA) $)^{(8)}$.

The multifunctional cytokine tumour necrosis factor-alpha (TNF- $\alpha$ ) plays a central part in the inflammatory cascade that is a key feature in atherosclerosis ${ }^{(9)}$. TNF- $\alpha$ levels correlate with progression of early carotid atherosclerosis and it is also a marker for recurrent coronary events after a previous myocardial

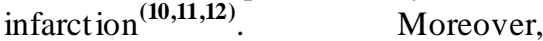
Proinflammatory cytokines, such as interleukin (IL)-6 and TNF- $\alpha$ play important roles in coronary arterial diseases by regulating inflammation, cellular adhesion, production of growth factors ${ }^{(13 \& 10)}$.

Iron is physiologically essential, but excess iron can also be a toxic and lead to the formation of a cascade of free radicals ${ }^{(\mathbf{1 4}, 15)}$. Iron was reported as an important factor in the process of atherosclerosis ${ }^{\mathbf{( 1 6 )}}$. Also, high levels of body iron, high LDL-cholesterol and antioxidant deficiency are regarded as oxidative risk factors for ischemic heart diseases ${ }^{(\mathbf{1 7})}$. Association between serum iron levels and pathogenes is of ischemic heart diseases is controversial. Whereas most data show no as sociation, some have raised the possibility of a causal role, while others have suggested a protective effect of iron. Roles of serum iron and its relation with cardioprotective IGF-1, proinflamatory cyokines (TNF and IL-6) in patients with acute myocardial infarction and unstable angina are indistinctive.

The aim of this investigation was to verify the role of inflammatory process and IGF-1 in patients with AMI and UA as well as to investigate the relationship of circulating IL-6, $\mathrm{TNF} \alpha$, IGF-1 and lipid profile with serum iron in these patients population. 


\section{SUBJECTS \& METHODS}

\section{Study population}

This study was carried out throughout co-operation between departments of Physiology, Biochemistry and Internal Medicine in Assiut Faculty of Medicine. The study was approved by the Assiut University Ethics Committee and every participant signed the informed consent before enrollment.

The research enrolled 36 male patients with acute coronary syndromes (18 patients with AMI of mean age $52 \pm 8$ years, and 18 patients with UA of mean age $54 \pm 7$ years) and 6 control male subjects (of mean age $50 \pm 10$ years). All patients were recruited from the Cardiac Clinic unit of Internal Medicine in Assiut University Hospital.

The normal volunteers had normotension (blood pressure: systolic < $140 \mathrm{~mm} \mathrm{Hg}$ and diastolic $<90 \mathrm{~mm} \mathrm{Hg}$ ), normal resting ECG with no past history or evidence of cardiovascular disease or diabetes mellitus. The present study did not include patients or control subjects with a history of neoplastic, hepatic, thyroid, infectious, autoimmune or peripheral atherosclerotic disease, any surgical procedure in the preceding 6 months or under treatment with antiinflammatory and/or lipid lowering drugs.

Patients with AMI were defined as presence of typical prolonged chest pain accompanied by serial changes on the standard 12-lead electrocardiogram and significant (twofold more than the upper normal range) increase in markers of myocardial damage as creatine kinase (CK), lactic dehydrogenase (LDH) or Troponine- T. Patients with UA were defined as anginal pain at rest occurring during the preceding 6 hours with transient significant ischemic ST-segment or T-wave changes or both, without significant increases in markers of myocardial damage (CK, LDH, Troponine T).

All patients were admitted to hospital with in 6 hours from the onset of chest pain. All patients underwent medical treatment with combination of standard medications, including nitrates, $\quad \beta$-adrenergic blockers, calcium antagonists, low molecular weight heparin and antiplatelet drugs such as aspirin and/or clopidogrel.

AMI and UA Patients were randomized and selected according to their serum iron into low, normal and high serum iron subdivision. Low serum iron levels were less than 38 $\mu \mathrm{g} / \mathrm{dl}$, normal serum iron levels were from $38 \mu \mathrm{g} / \mathrm{dl}$ to $158 \mu \mathrm{g} / \mathrm{dl}$, and high serum iron levels were higher than $158 \mu \mathrm{g} / \mathrm{dl}^{(\mathbf{1 8})}$.

The prevalence of major risk factors and medications among the normal control subjects and the two groups of patients are shown in table 1. 
Table 1: Risk factors and medications used in the acute myocardial infarction (AMI), in unstable angina (UA) and control subjects involved in this study.

\begin{tabular}{|l|l|l|l|}
\hline Patient char acteristics & $\begin{array}{l}\text { AMI Group } \\
(n=18)\end{array}$ & $\begin{array}{l}\text { UA Group } \\
(n=18)\end{array}$ & $\begin{array}{l}\text { Control Group } \\
(n=6)\end{array}$ \\
\hline Age (years) & $52 \pm 8$ & $54 \pm 7$ & $50 \pm 10$ \\
\hline Smoking & 15 & 14 & 2 \\
\hline Hypertension & 15 & 10 & 0 \\
\hline Diabe tes Mellitus & 10 & 7 & 0 \\
\hline Hypercholestremia & 16 & 14 & 2 \\
\hline Body mass index ( $\geq \mathbf{2 5} \mathbf{~ k g / \mathbf { m } ^ { 2 } )}$ & 13 & 14 & 3 \\
\hline Family History of CAD & 9 & 6 & 0 \\
\hline Medications: & & & \\
Nitrates & 18 & 18 & 0 \\
$\beta$-blockers & 13 & 11 & 0 \\
Calcium antagonists & 10 & 7 & 0 \\
ACE inhibitors & 10 & 8 & 0 \\
Aspirin & 18 & 11 & 0 \\
Clopidogrel & 15 & 13 & 0 \\
LMWH & 18 & 18 & 0 \\
Thrombolytic therapy & 18 & 0 & 0 \\
\hline
\end{tabular}

ACE = Angiotensin Converting Enzyme, LMWH = Low Molecular Weight Heparin, $C A D=$ Coronary Artery disease, $n=$ number .

\section{Laboratory measurements}

- Blood sample (5 ml) was obtained from healthy controls and patients within $1 \mathrm{~h}$ of admission. The samples were taken slowly from an antecubital vein and were transferred to chilled sterile disposable tubes without anticoagulant. The disposable tubes were promptly centrifuged at 3000 r. p.m. for $20 \mathrm{~min}$. at $4{ }^{\circ} \mathrm{C}$ within 1 $\mathrm{h}$ of drawing to separate serum then serum immediately stored at $-70{ }^{\circ} \mathrm{C}$ until used.

- Serum iron was measured by atomic absorption/flame, emission spectrophotometer (A-A630-O2) at wave length $2483 \mathrm{~nm}$ and lamp current $10 \mathrm{~mA}^{(\mathbf{1 9 )}}$.
- Enzyme-linked imunosorbent assays (ELISA) were performed for measuring concentrations of TNF- $\alpha$ (Cat. No. KAC 1571), IL-6 (Cat. No. M1916) and IGF-1 (Cat. No. M 1915) using Biosurce Europe commercial kits with monoclonal antibodies against each substance and following the instruction supplied with each kit. The apparatus used was Ansoth, 2000 manufactured in Austria.

- Fasting levels of Lipid total cholesterol levels were measured by quantitative enzymatic colorimetric determination using Stanbiocholesterol LiquiColor kit (procedure No. 1010), measured by spectrophotometer according to the method of Flegg, (1973) ${ }^{(20)}$. HDL 
levels were measured by using Stanbio-HDL Cholesterol kit (procedure No. 0599) according to the method described by Finley $\mathbf{( 1 9 7 8 )}^{\mathbf{( 2 1 )}}$. Trigyceride levels were measured by using Stanbio Liquicolor Trigycerides kit (procedure No. 2100) according to the method described by Bucolo and David (1973) ${ }^{(22)}$. The LDL was calculated by subtracting both levels of HDL and one fifth of triglycerides from the levels of total cholesterol $^{(23)}$. The atherogenic index was calculated as the product of total cholesterol/ $\mathrm{HDL}^{(24)}$.

\section{Statistical analysis}

Data are expressed as mean $\pm \mathrm{SE}$ for all parameters. The data were analyzed by using GraphPad Prism data analysis program (GraphPad Software, Inc., San Diego, CA, USA). For the comparison of statistical significance between patients and normal subjects, Student NewmanKeuls t-test for unpaired data was used. For multiple comparisons, oneway analysis of variance (ONEWAY-A NOVA) test followed by least Significant Difference (LST) was used. Values were accepted as being statistically significant if a $\mathrm{P}$ value was less than 0.05. Correlations of serum iron with the other variables were assessed using Spearman's nonparametric correlation coefficient $\rho$. A value of $P<0.05$ was considered statistically significant.

\section{RESULTS}

AMI and UA patients with low, normal or high serum iron revealed a strong evidence of inflammation and reduced cardioprotective agents. A summary of these results is shown in

Figures 1-9 and Table1- 2.

Results of demographic data:

Baseline characteristics of the cases and controls are shown in (table 1). Risk factors (age, smoking, hypertension, and diabetes mellitus and increase body mass index above $25 \mathrm{~kg} / \mathrm{m}^{2}$ ) occurred more frequently among patients.

Results of measured laboratory parameters:

Relation to serum iron: Estimation of serum iron (mg/ dl) showed significant reduction in both AMI and UA patients with low and normal serum iron when compared with that of control value. However, it significantly increased in both patients groups with high serum iron as compared with that of control subjects. Whereas; there were nonsignificant differences in serum iron levels between AMI and UA patients either with low, normal or high serum iron. These results are summarized in table (2-a).

Relation to Pro-inflammatory cytokines: Both measured proinflammatory cytokines as serum IL-6 and TNF- $\alpha$ (pg/ ml) increased significantly $(\mathrm{P}<0.001)$ in $\mathrm{AMI}$ and UA patients with low, normal and high serum iron when compared with control mean value as shown in table (2-a).

AMI patients with low serum iron exhibited significant higher serum levels of IL-6 (P<0.05) and TNF- $\alpha$ (P $<0.01)$ when compared with UA patients with low serum iron. While, AMI patients with normal serum iron displayed significant decrease of IL-6 $(\mathrm{P}<0.01)$ and increase $\mathrm{TNF} \alpha(\mathrm{P}$ $<0.05)$ as compared with UA patients 
with normal serum iron. Furthermore, IL-6 decreased significantly (P $<0.001$ ) in AMI patients with high serum iron in comparison to that of UA patients with high serum iron (table $2-\mathrm{a}$ ).

Statistic analysis showed significant increase serum levels of IL-6 $(\mathrm{P}<0.001)$ and TNF $\alpha$, $(\mathrm{P}<0.05$ and $\mathrm{P}<0.001$ respectively) in $A M I$ patients with low serum iron in relation to that of AMI patients with normal or high serum iron (figure 1a). While in UA patients either with low, normal or high serum iron, there were non-significant changes in the levels of IL- 6 and TNF $\alpha$.. A summary of these findings is shown in figure (2-a).

Relation to IGF-1: serum levels of IGF-1 (pg/ml) decreased significantly in AMI with low, normal and high serum iron and in UA patients with low and normal serum iron when compared with control value. Although in UA patients with high serum iron it decreased insignificantly in relation to that of control as shown in table (2- a).

AMI patients with low serum iron exhibited significant $(\mathrm{P}<0.05)$ lower serum levels of IGF- 1 when compared with UA patients with low serum iron. While AMI patients with normal iron or high serum iron showed nonsignificant changes in IGF-1 levels as compared with UA patients with normal or high serum iron ( table 2 a).

Moreover, IGF-1 significantly decreased $(\mathrm{P}<0.001$ and $\mathrm{P}<0.01$ respectively) in AMI patients with low serum iron in relation to that of AMI patients with normal and high serum iron (figure 1-b). Likewise, there was a significant reduction in the levels of IGF-1 $(\mathrm{P}<0.01)$ in UA patients with low serum iron in comparison to UA patients with normal or high serum iron (figure 1-b).

Relation to risky lipid profile: As comparable to the control subjects, assessment of risky lipids (cholesterol, triglyceride and LDL-C) and atherogenic index revealed significant increase in both patients groups (table 2 - b).

AMI patients with low serum iron showed significant higher LDL-C (P $<0.01)$, cholesterol $(\mathrm{P}<0.001)$ and atherogenic index $(\mathrm{P}<0.01)$ but nonsignificant increase of triglyceride level when compared with UA patients with low serum iron (2-b). While AMI patients with normal or high serum iron displayed nonsignificant changes in the levels of risky lipids except (LDL-C) as comparable to that of UA patients with normal or high serum iron( table $2-b)$.

There was a significant increase mean values of cholesterol, LDL-C and atherogenic index in AMI patients with low serum iron as comparable to that of AMI patients with normal or high serum iron (figure 1-C). Meanwhile, LDL-C and triglyceride levels significantly (P $<0.05)$ increased in UA patients with low serum iron in comparable to UA patients of normal or high iron (figure 2- C).

Relation to cardioprotective lipid pr ofile: Serum HDL-C (mg/dl), cardioprotective lipid, diminished significantly $(\mathrm{P}<0.001)$ in both patients groups versus control mean value as shown in table (2-b). 
AMI patients with low serum iron exhibited significant decrease serum levels of HDL-C $(P<0.05)$ when compared with UA patients with low serum iron. However, there was nonsignificant change as regard HDL-C in AMI patients with normal or high serum iron when compared with that of UA patients (table $2-b$ ).

In addition, HDL-C significantly ( $\mathrm{P}<0.01$ and $\mathrm{P}<0.001$ respectively) decreased in AMI patients with low serum iron as comparable to that of AMI patients with normal or high serum iron (figure 1-c). Also, in UA patients with low serum iron, there was a significant reduction in the levels of HDL-C (P <0.05) in comparison to UA patients with normal or high serum iron. A summary of these results is shown in figure (2- c).

Correlation:

In AMI patients with high serum iron, there was a statistically significant positive correlation of serum iron with HDL-C and IGF-1 as well as significant negative correlation with IL-6, TNF $\alpha$, cholesterol, LDL-C, triglyceride and atherogenic index (Fig.3 and 4). Likewise, in AMI patients with low serum iron, similar significant correlations were proofed except triglyceride level (figure 5 and 6).

UA patients with low iron showed statistically positive correlation between serum iron and IGF-1 and HDL-C and negative correlation with TNF $\alpha$, IL-6, atherogenic index and LDL-C (figure 7 and 8). As well, UA patients with high serum iron exhibited significant negative correlations between serum iron with TNF $\alpha$, IL-6, triglyceride and atherogenic index but non significant relations with other parameters (figure 9). 
Table (2-a): Comparis on mean values of serum iron, IGF -1, IL-6, TNF $\alpha$, between healthy control and both AMI \& UA patients with low, normal \& high serum iron.

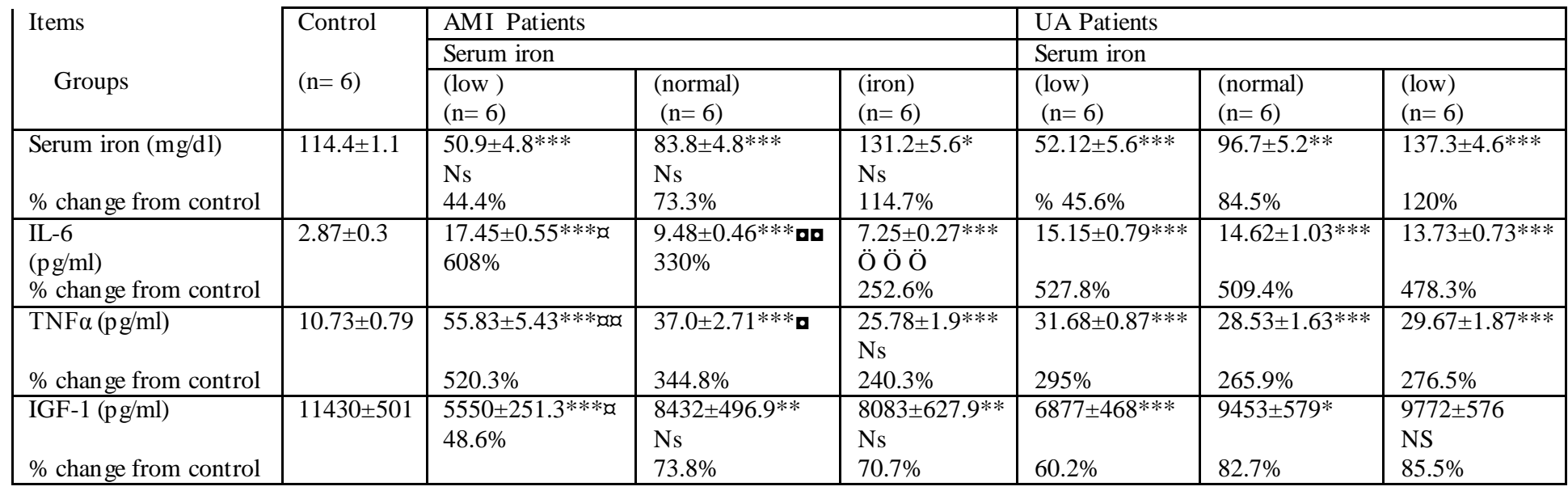

All values represent means \pm SE and were analyzed by A Student Newman-Keuls t-test. AMI: acute my ocardial infarction, UA: unstable angina, IGF-1: insulin like growth factors -1, TNF $\alpha$ : tumor necrotic factor $\alpha$, IL-6: interleukin-6. HDL-C = high density lipoprotein cholesterol, LDL-C = low density lipoprotein cholesterol. Ns: non significant.

* Showing comparison between all groups Vs. control ( $*=\mathrm{P}<0.05$, ** $=\mathrm{P}<0.01, * * *=\mathrm{P}<0.001)$.

a Showing comparison between AMI patients with low iron Vs. UA patients with low iron ( $a \mathrm{P}<0.05$, a $\mathrm{P}<0.01$, aad $\mathrm{P}<0.001$ )

- Showing comparison between AMI patients with normal iron Vs. UA patients with normal iron $(\mathbf{0}=\mathrm{P}<0.05$, $\mathbf{0} \mathbf{0}=\mathrm{P}<0.01)$.

Ö Showing comparison between AMI patients with high iron Vs. UA patients with high iron (Ö Ö Ö = P <0.001). 
Table (2- b): Comparison mean values of LDL-C, cholesterol, triglyceride, atherogenic index and HDL-C between healthy control and both AMI \& UA patients with low, normal \& high serum iron.

\begin{tabular}{|c|c|c|c|c|c|c|c|}
\hline \multirow{3}{*}{$\begin{array}{l}\text { Items } \\
\text { Groups }\end{array}$} & \multirow{3}{*}{$\begin{array}{l}\text { Control } \\
(n=6)\end{array}$} & \multicolumn{3}{|l|}{ AM I Patients } & \multicolumn{3}{|l|}{ UA Patients } \\
\hline & & \multicolumn{3}{|l|}{ Serum iron } & \multicolumn{3}{|l|}{ Serum iron } \\
\hline & & $\begin{array}{l}\text { low }) \\
(n=6)\end{array}$ & $\begin{array}{c}\text { (normal) } \\
(n=6)\end{array}$ & $\begin{array}{l}(\text { low }) \\
(n=6)\end{array}$ & $\begin{array}{l}\text { (normal) } \\
(n=6)\end{array}$ & $\begin{array}{l}(\text { low ) } \\
(n=6)\end{array}$ & $\begin{array}{l}\text { (normal) } \\
(n=6)\end{array}$ \\
\hline LDL-C (mg/dl) & $85.38 \pm 1.42$ & $249.0 \pm 2.48 * * * a d$ & $160.7 \pm 4.49 * * *$ DD & $\begin{array}{l}145.2 \pm 2.0 * * * \\
\text { Ns }\end{array}$ & $157.7 \pm 2.24 * * *$ & $143.3 \pm 2.25 * * *$ & $146.5 \pm 2.39 * * *$ \\
\hline$\%$ change from control & & $291.6 \%$ & $188.2 \%$ & $170 \%$ & $184.7 \%$ & $167.8 \%$ & $171.6 \%$ \\
\hline $\begin{array}{l}\text { Cholesterol (mg/dl) } \\
\text { \% change from control }\end{array}$ & $\begin{array}{l}177.7 \\
\pm 5.04\end{array}$ & $\begin{array}{l}316.7 \pm 13.9 * * * \text { ada } \\
178.2 \%\end{array}$ & $\begin{array}{l}240.02 \pm 10.0^{* * * *} \\
\text { Ns } \\
135.1 \% \\
\end{array}$ & $\begin{array}{l}225.8 \pm 8.0 * * * \\
\text { Ns } \\
127.1 \% \\
\end{array}$ & $\begin{array}{l}235 \pm 7.64^{* * *} \\
132.2 \%\end{array}$ & $\begin{array}{l}223.3 \pm 8.03^{* * *} \\
125.7 \%\end{array}$ & $\begin{array}{l}224.7 \pm 7.86^{* * *} \\
126.4 \%\end{array}$ \\
\hline $\begin{array}{l}\text { Trigly ceride (mg/dl) } \\
\% \text { change from control }\end{array}$ & $174.7 \pm 2.34$ & $\begin{array}{l}203.0 \pm 4.47 * * * \\
\text { Ns } \\
116.2 \%\end{array}$ & $\begin{array}{l}199.8 \pm 3.0^{* * *} \\
\text { Ns } \\
114.4 \%\end{array}$ & $\begin{array}{l}187.3 \pm 3.8^{*} \\
\text { Ns } \\
107.2 \%\end{array}$ & $\begin{array}{l}208.3 \pm 4.22^{* * *} \\
119.2 \%\end{array}$ & $\begin{array}{l}191.5 \pm 3.25 * * \\
109.6 \%\end{array}$ & $\begin{array}{l}191.2 \pm 4.02^{* *} \\
109.4 \%\end{array}$ \\
\hline $\begin{array}{l}\text { Atherogenic index } \\
\text { (Cholesterol/ HDL-C } \\
\text { \% change from control }\end{array}$ & $3.05 \pm 0.09$ & $\begin{array}{l}11.75 \pm 1.45^{* * * a q} \\
385.2 \%\end{array}$ & $\begin{array}{l}6.45 \pm 0.85^{* *} \\
\text { Ns } \\
211.5 \% \\
\end{array}$ & $\begin{array}{l}5.2 \pm 0.55^{* * *} \\
\text { Ns } \\
170 \%\end{array}$ & $\begin{array}{l}6.28 \pm 0.39 * * * \\
205.9 \% \\
\end{array}$ & $\begin{array}{l}5.37 \pm 0.19 * * * \\
176.1 \% \\
\end{array}$ & $\begin{array}{l}5.62 \pm 0.43^{* * *} \\
184.3 \% \\
\end{array}$ \\
\hline $\begin{array}{l}\text { HDL-C (mg/dl) } \\
\% \text { change from control }\end{array}$ & $57.50 \pm 1.06$ & $\begin{array}{l}26.83 \pm 2.6^{* * * a} \\
46.7 \%\end{array}$ & $\begin{array}{l}39.83 \pm 1.96 * * * \\
\mathrm{Ns} \\
69.3 \%\end{array}$ & $\begin{array}{l}43.17 \pm 2.12 * * * \\
\text { Ns } \\
75.1 \%\end{array}$ & $35.50 \pm 1.52^{* * *}$ & $\begin{array}{l}41.67 \pm 1.45 * * * \\
72.5 \%\end{array}$ & $40.0 \pm 1.21^{* * *}$ \\
\hline
\end{tabular}

All values represent means \pm SE and were analyzed by A Student Newman-Keuls t-test. AMI: acute my ocardial infarction, UA: unstable angina, IGF-1: insulin like growth factors -1, TNF $\alpha$ : tumor necrotic factor $\alpha$, IL-6: interleukin-6. HDL-C = high density lip oprotein cholesterol, LDL-C = low density lip op rotein cholesterol. Ns: non significant.

* Showing comparison between all groups Vs. control $(*=\mathrm{P}<0.05$, ** $=\mathrm{P}<0.01$, ***= $\mathrm{P}<0.001)$.

a Showing comparison between AMI patients with low iron Vs. UA patients with low iron ( $a \mathrm{P}<0.05$, a $\mathrm{P}<0.01$, aad $\mathrm{P}<0.001)$.

- Showing comparison between AMI patients with normal iron Vs. UA patients with normal iron $(\mathbf{0}=\mathrm{P}<0.05$, $\mathbf{0} \mathbf{0}=\mathrm{P}<0.01)$.

Ö Showing comparison between AMI patients with high iron Vs. UA patients with high iron ( $0 \ddot{O}$ Ö Ö $=P<0.001)$. 

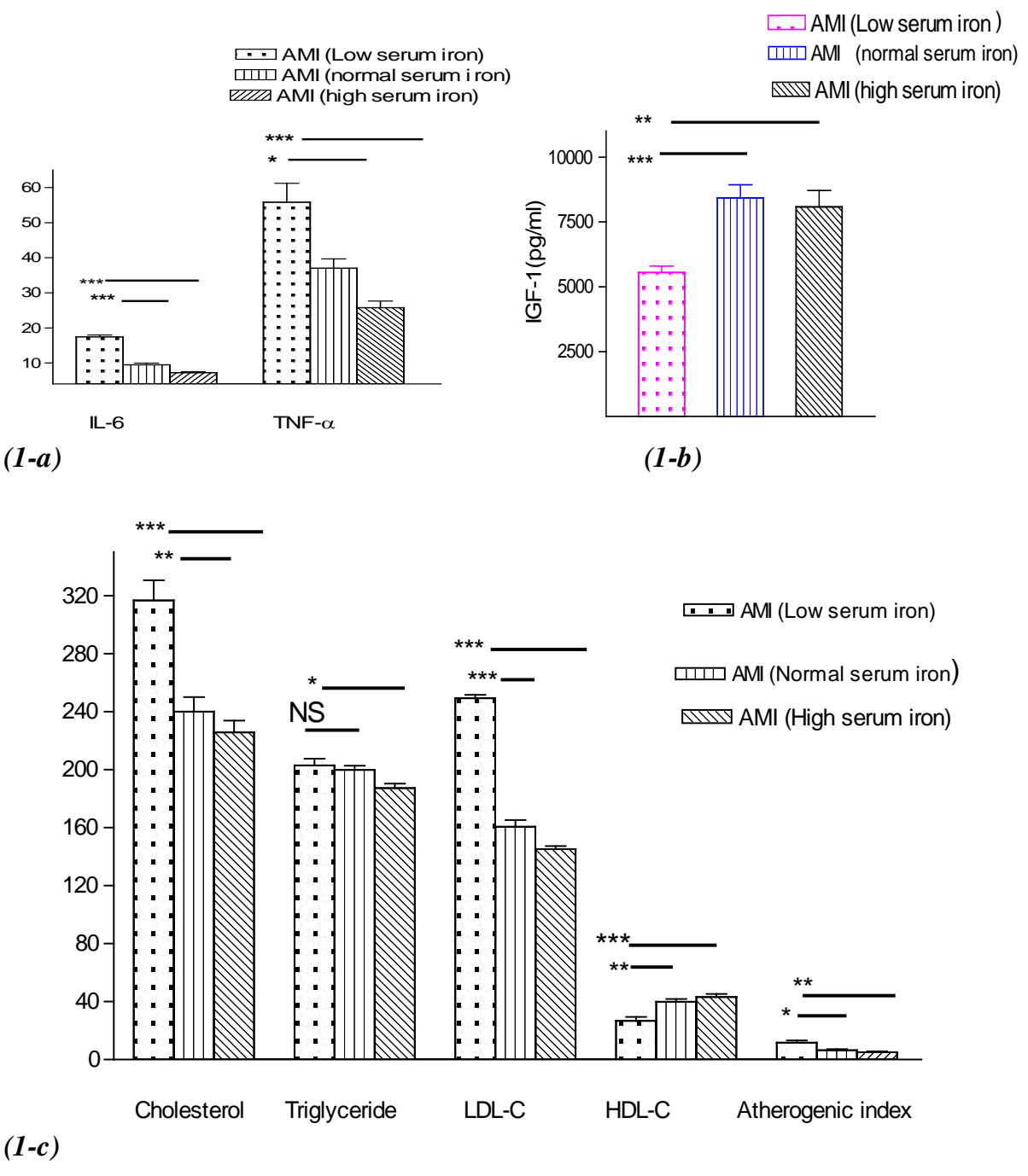

Fig. (1-a, $b$ and c): Mean values of IL-6 and TNFa (1-a), IGF-1 (1-b), cholesterol, Triglyceride, LDL-C, HDL-C and atherogenic index (1-c) of AMI patients with low serum iron versus $A M I$ patients with normal and high serum iron. $(* * *=P<0.001, * *=P<0.01$ and $*=P<0.05, N S=$ non significant). $H D L-C=$ high density lipoprotein cholesterol, $L D L-C=$ low density lipoprotein cholesterol. 

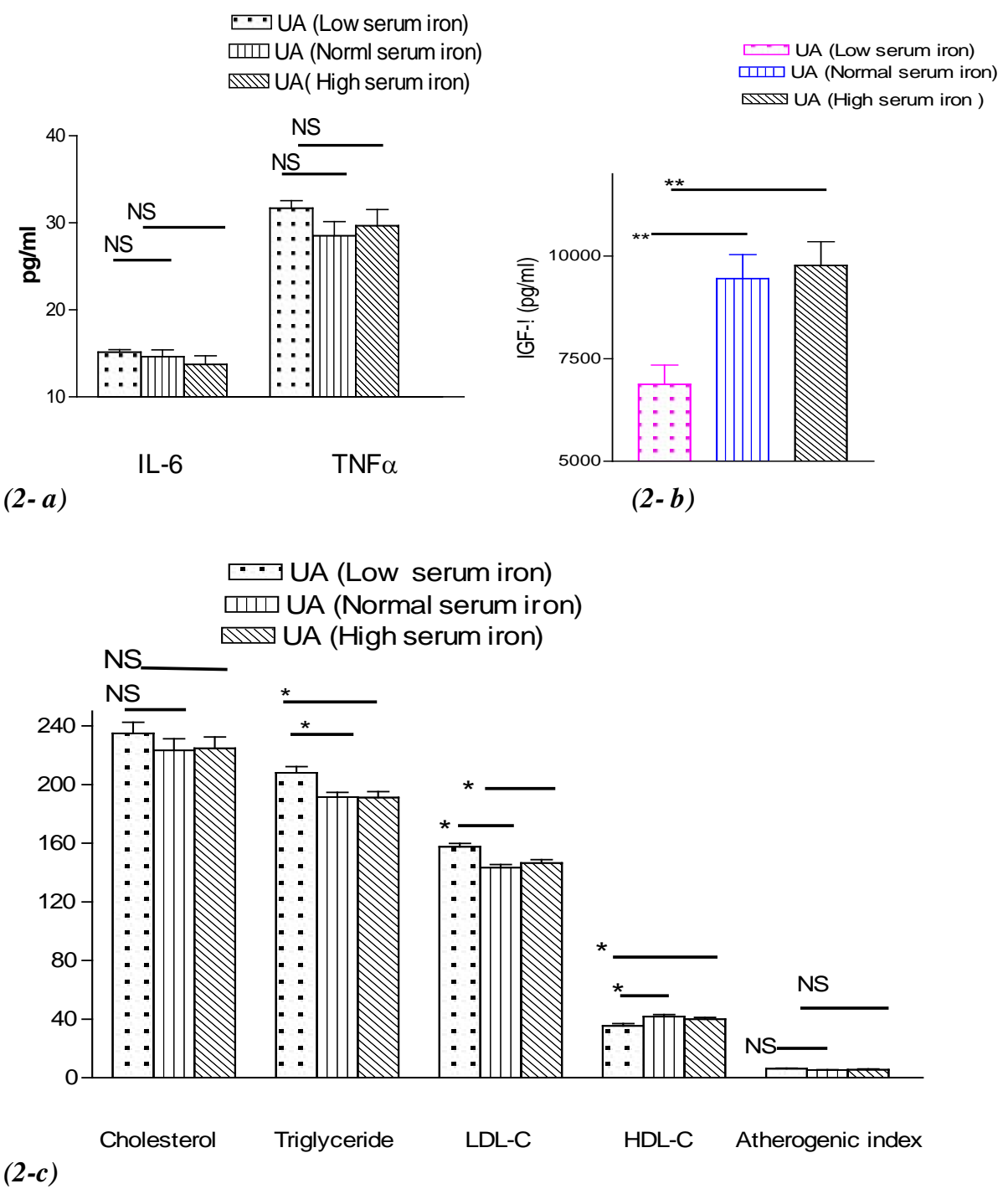

Fig. (2- $a, b$ and c): Mean values of IL-6 and TNF $\alpha$, (2-a), IGF-1 (2-b), cholesterol, Triglyceride, LDL-C, HDL-C and atherogenic index (2-c) of UA patients with low serum iron versus $U A$ patients with normal and high serum iron.

NS = non significant. $(*=P<0.05),\left({ }^{* *}=P<0.01\right)$. HDL $-C=$ high density lipoprotein cholesterol, $\mathrm{LDL}-\mathrm{C}=$ low density lipoprotein cholesterol. 


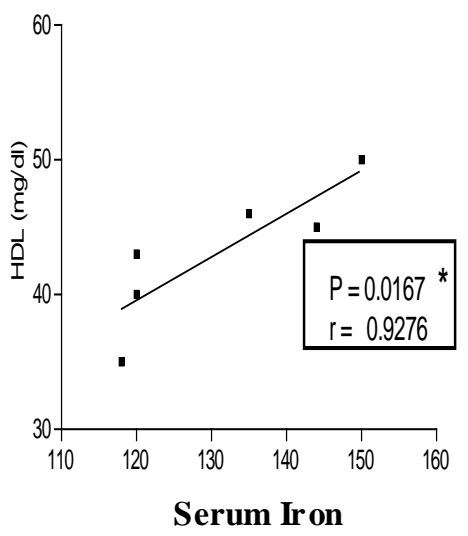

(3-a)

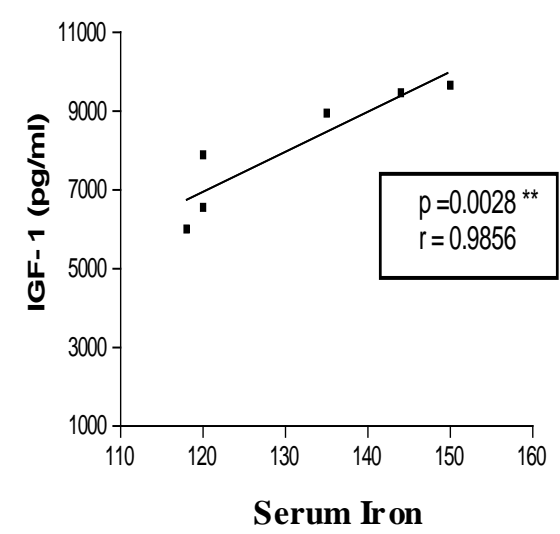

(3-b)

Fig. (3-a and b): Correlation and linear regression of serum iron with HDL-C and IGF-1 in AMI patients with high serum iron.

- Cholesterol $p=0.0167^{*}$ $r=-0.9276$

O LDL-C $\mathrm{P}=0.0028$ ** $r=-0.98$

7 Triglyceride $P=0.0333$ * $r=-0.8971$

口 Atherogenic index $P=0.0028$ * $r=-0.9856$

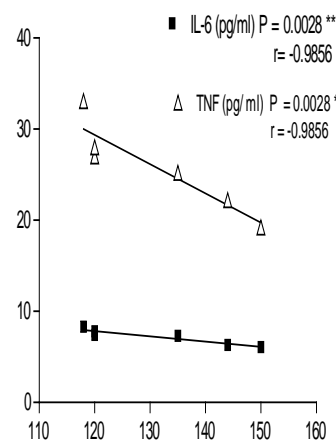

Serum Iron

(4-a)

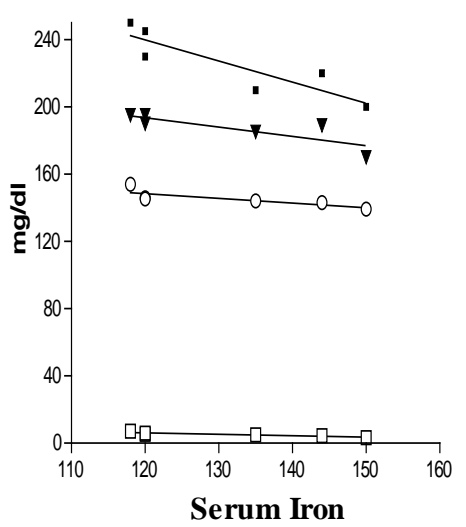

(4-b)

Fig. (4-a and b): Correlation and linear regression of serum iron with $T N F a$ and IL-6, cholesterol, LDL-C, triglyceride and atherogenic index (4-b) in AMI patients with high serum iron. 


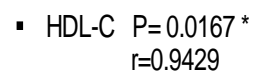

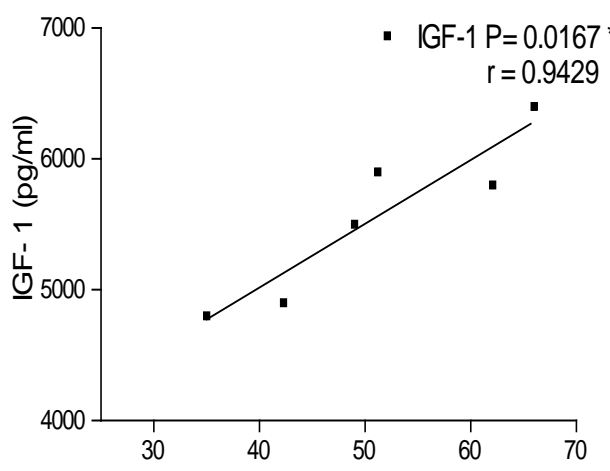

Serum Iron

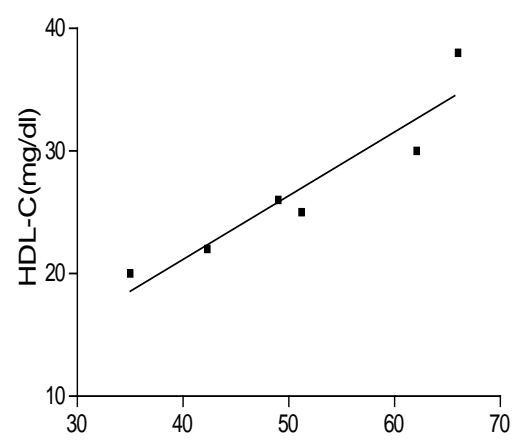

Serum Iron

Fig. (5-a and b): Correlation and linear regression of serum iron with insulin like growth factor 1 (IGF-1) and HDL-C in AMI patients with low serum iron.

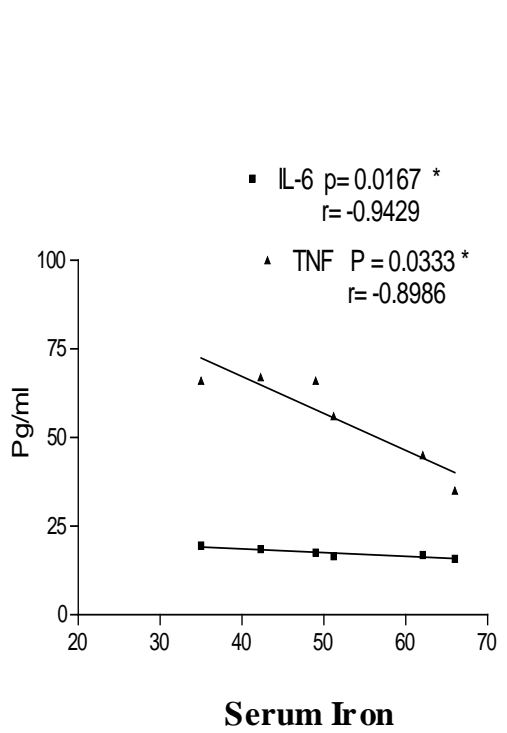

(6-a)

Fig. (6-a and b): Correlation and linear regression of serum iron and Tumor necrotic factor (TNFa) \& interleukin-6 (IL-6), cholesterol, LDL-C, triglyceride and atherogenic index in AMI patients with low serum iron. 


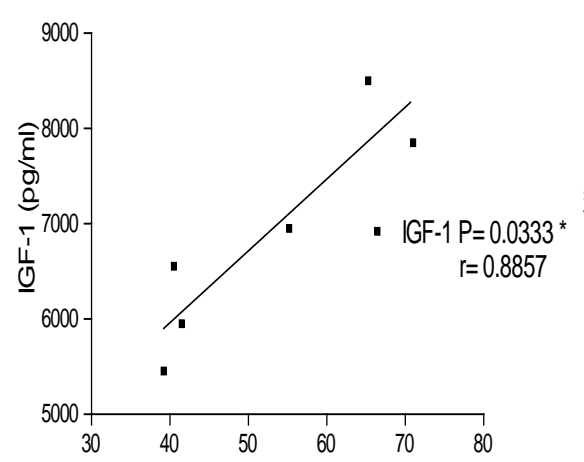

Serum Iron

(7-a)

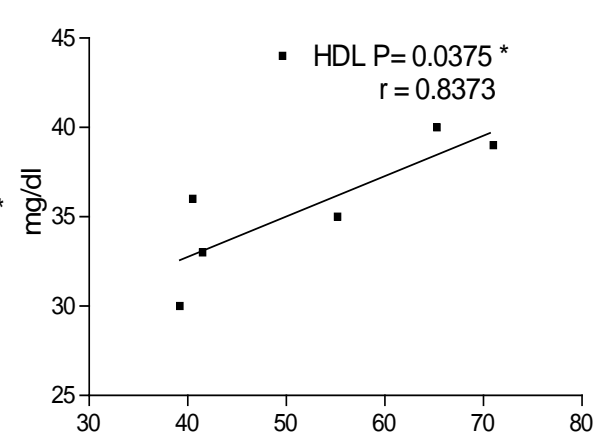

Serum Iron

(7-b)

Fig. (7-a and b): Correlation and linear regression of serum iron with insulin like growth factor 1 (IGF-1) and HDL-C in UA patients with low serum iron.

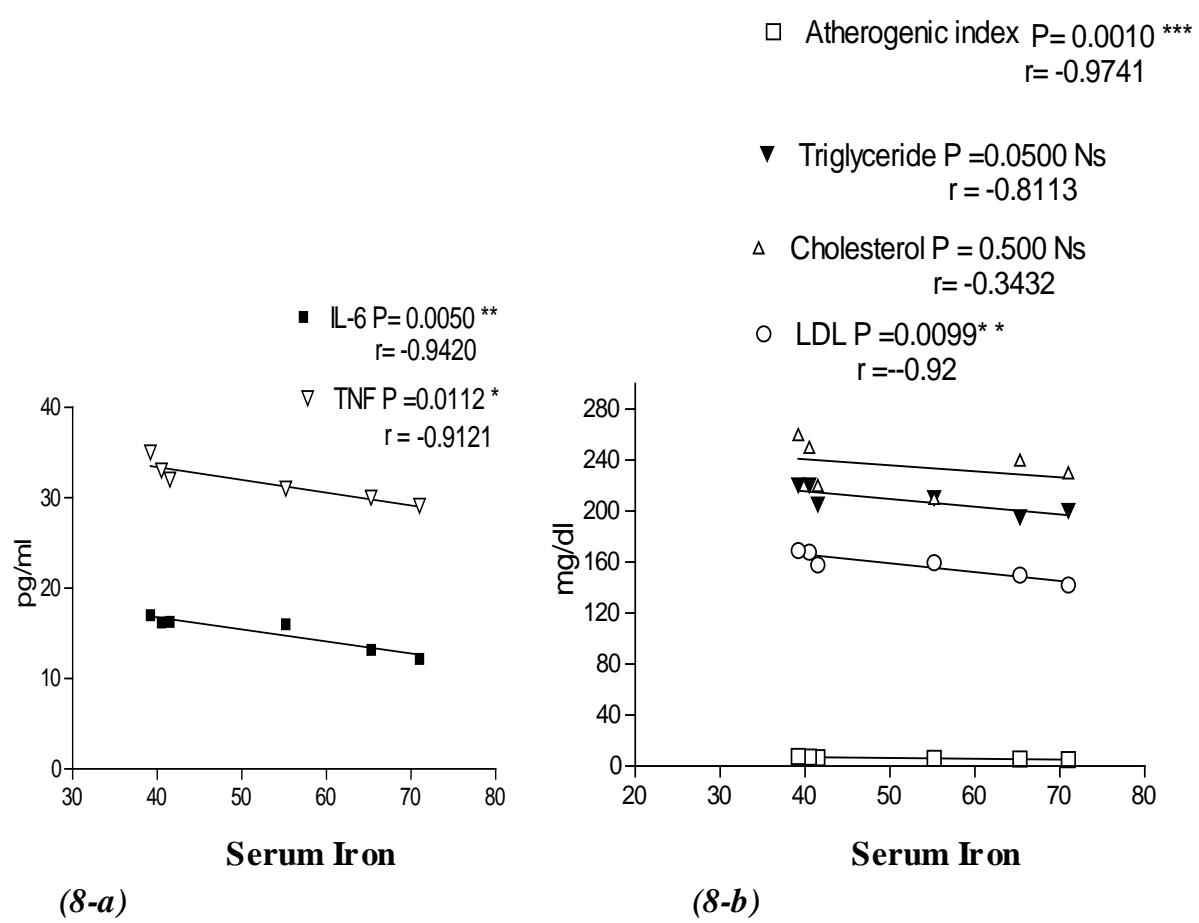

Fig. (8-a and b): Correlation and linear regression of serum iron and Tumor necrotic factor (TNFa), interleukin-6 (IL-6), cholesterol, LDL-C, triglyceride and atherogenic index in UA patients with low serum iron. 
- Cholesterol $P=0.06 \mathrm{NS}, \mathrm{r}=-0.78$

4 LDL-C $P=0.79$ NS, $r=0.14$

$\nabla$ Triglyceride $P=0.04 * r=-0.83$

- Atherogenic index $P=0.004$ ** $r=-0.95$

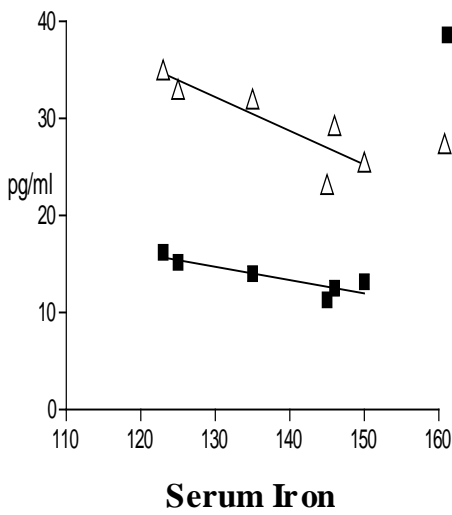

(9-a)

IL-6 $P=0.021$ *

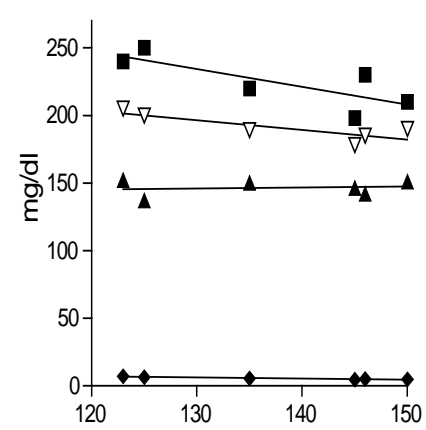

(9-b)

Serum Iron

Fig. (9-a and b): Correlation and linear regression of serum iron with tumor necrotic factor (TNFa), interleukin-6 (IL-6), cholesterol, LDL-C, triglyceride and atherogenic index in UA patients with high serum iron.

\section{DISCUSSION}

Whereas a large body of evidence exists to confirm the pathophysiological role of inflammation in atherosclerosis and in rupture of atherosclerotic plaques, minimal informations are available regarding its role in ischemic heart disease and the 'protective' and 'counterbalancing' role of IGF-1 in this cases. Also, iron is known as a physiologically essential agent, but the association between serum iron level and pathogenesis of ischemic heart diseases is controversial. Whereas most data show no association, some have raised the possibility of a causal role, while others have suggested a protective effect of iron. Our knowledge about the association between serum iron and inflammatory markers (TNF- $\alpha$ and IL-6) and IGF-1 is still incomplete. In this report, we hypothesized that inflammatory cytokines, IGF-1, serum lipid and iron may influence on pathogenesis of AMI and UA. To illustrate these influence and to test our hypothesis, we carried out this investigation. To accomplish our goals, we set up three subgroups of AMI and UA patients with low, normal or high serum iron as well as control subjects. The serum levels of IL-6, TNF- $\alpha$, IGF- 1 in control subjects and patients with AMI and UA, as well as the potential correlations of these parameters with serum iron and lipids in different studied groups were estimated. 
The present study showed predominance of smoking, hypertension, diabetes, hypercholestremia and increase body mass index in both AMI and UA patients that coincide with previous investigators ${ }^{(25,26)}$.

Both AMI and UA patients with low, normal or high serum iron were characterized by increasing pro-inflammatory cytokines as TNF- $\alpha$ and IL-6.

In this study, the elevated levels of inflammatory cytokines, TNF- $\alpha$ and IL-6, in AMI and UA goes in line with other previous

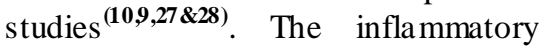
process is involved throughout the different stages of atherosclerosis. The mechanisms of actions and roles of TNF $\alpha$ in pathogenesis of AMI and UA are supported by several observations. TNF $\alpha$ plays a central part in the inflammatory cascade and correlates with the progression and recurrence of myocardial infarction $^{(\mathbf{9}, 28)}$. In addition, the vulnerability of an atherosclerotic plaque is related to the presence of inflammation since it plays a vital role in disruption of the fibrous cap, which is a major pathophysiological event for the development of AMI and $\mathrm{UA}^{(8)}$. Furthermore, Kai et al., $(1998)^{(29)}$ and Mallat et al. (2001) $)^{(30)}$ reported that pro-inflammatory cytokines produced by lymphocytes and macrophages, inhibit the collagen synthesis by smooth muscle cells, and enhance the expression of proteases (matrix metalloproteinases, MMPs) that lead to proteolytic destruction of connective tissue matrix in vulnerable atherosclerotic plaques.
The association between TNF- $\alpha$ and ischemic heart diseases are supported by many investigations. TNF- $\alpha$ is related to several common risk factors for ischemic heart diseases ${ }^{(25)}$. Smoking is a strong risk factor for the development of cardiovascular diseases and also contributes to variation of $\mathrm{TNF}-\alpha$ protein levels in healthy subjects ${ }^{(31)}$. In addition, TNF- $\alpha$ is synthesized by adipocytes and increased adiposity (obesity) leads to raised levels of TNF- $\alpha^{(32,33)}$ as well as elevated risk for cardiovascular diseases. So that, the increased levels of TNF- $\alpha$ seen in association with ischemic heart may be attributable to environmental stimuli of inflammatory processes (as smoking and obesity), or genetic variations that contribute to individual differences in TNF- $\alpha$ levels ${ }^{(25)}$.

The elevated level of IL- 6 in both AMI and UA patients in the current study and its role in ischemic heart disease coincide with the other studies $^{(34,35)}$. Interleukin-6 is the main regulators of the acute-phase response of inflammation, often acting in synergistic and cascade-like reactions and is capable of inducing the synthesis of the whole spectrum of acute-phase proteins ${ }^{(\mathbf{3 6})}$. It is produced by several different cell types such as fibroblasts, monocytes, macrophages, $\mathrm{T}$ and $\mathrm{B}$ lymphocytes, endothelial cells and myocytes ${ }^{(37)}$. Furthermore, IL-6 protein and gene has been shown to be present in the human atherosclerotic vessel wall and is believed to play a role in the atherosclerotic process ${ }^{(38)}$ and acute coronary disease such as AMI and $\mathrm{UA}^{(39,34,35)}$. 
Insulin like growth factor-1 (IGF-1) decreased in AMI and UA patients with low, normal or high serum iron.

In our study, the significant reduction of serum level of IGF-1 in both AMI and UA patients in relation to controls is in agreement with previous reports and suggests the cardioprotective role of IGF-1 in selected patients' populations. The association between IGF-1 and ischemic heart disease is studied by other investigators ${ }^{\mathbf{4 0 2 6})}$. IGF-I has insulin-like metabolic effects and originates from the liver under stimulation of growth hormone (GH). It mediates many of the $\mathrm{GH}$ anabolic and growth actions ${ }^{(41)}$. IGF binding protein-3 (IGFBP-3) inhibits the bioactivity of IGF-I by sequestering IGF-I into a circulating reservoir, thereby reducing the free active fraction of IGF-I in the circulation. Therefore, decreased IGF-1 and increased IGFBP-3 were associated with increasing risk of developing ischemic heart disease ${ }^{(40)}$. Because IGF-1 is important for tissue repair and cell proliferation, it has been implicated in the pathogenesis of atherosclerosis ${ }^{(3)}$, progression of focal coronary atherosclerosis $\left({ }^{\mathbf{4 2}}\right)$, is chemic heart diseases ${ }^{(\mathbf{6})}$ and increasing mortality of $\mathrm{AMI}^{(26)}$. Furthermore, Hong et al., 1996 ${ }^{\mathbf{( 4 3 )}}$, Vaessen et al.,2001 ${ }^{(\mathbf{4 4 )}}$ and Mojgan et al., 2006 (26) reported that absence of 192- and 194-bp alleles of the IGF-I promoter was associated with declining IGF-1 production and increased risk of myocardial infarction. These special effects of IGF-1 may be attributed to its ability to regulate myocardial structure and function and promote cardiac muscle growth, differentiation, promoting tissue remodeling and survival during myocardial ischemia ${ }^{(6)}$.

One of the most important property of IGF-I is its ability to suppresses myocardial apoptosis and improves myocardial function ${ }^{(5 \& 45)}$. IGF-I may also increase cardiac output and myocardial contractility, which may contribute to improved survival after a $\mathrm{AMI}^{(6)}$. Taken collectively, these findings imply important roles for IGF-1 in pathophysiology of ischemic heart diseases and decrease the incidence of these cases. Potential therapeutic and prophylactic situation of IGF-1 in these cases need further studies.

Risky lipids (cholesterol, triglyceride, LDL-C) and atherogenic index increased whereas cardio-protective lipid, HDL-C declined in both AMI and UA patients.

Alteration of serum lipid profile (significant increase of cholesterol, triglyceride, LDL-C, atherogenic index and highly significant decrease, $\mathrm{P}<0.001$, of HDL-C) in both AMI and UA patients evident in this report harmonizes with other investigations. High triglyceride and low HDL-C, were at least as powerful a predictor of ischemic heart diseases (IHD) as is olated high $\mathrm{LDL}_{-} \mathrm{C}^{(46,47,48)}$. In support of this role, triglyceride appears to be closely related to a series of potentially atherogenic and thrombogenic changes, such as small, dense LDL particles ${ }^{(\mathbf{4 9})}$, prolonged postprandial hypertriglyceridemia ${ }^{(50)}$. Also, triglyceride increases accumulation of chylomicron remnants ${ }^{(\mathbf{5 0})}$, higher concentrations of 
plasminogen activator inhibitor- $1^{(\mathbf{5 1 , 5 2 )}}$ and higher concentrations of coagulation factor $\mathrm{VII}^{(53)}$. So, it seemed more meaningful to focus on the combined lipid profile, high TGlow HDL-C, as a risk factor of IHD than on high TG and low HDL-C as individual risk factors. Therefore, scientific efforts to prevent IHD should include intervention against high TG-low HDL-C, and not just against hypercholesterolemia.

A significant increase of atherogenic index (Cholesterol/HDL$\mathrm{C}$ ratio) in both AMI and UA patients in this study coincides with other studies. Isabelle Lemieux et al., $(2001)^{(54)}$ reported that total cholesterol/HDL-C ratio may be associated with more substantial alterations in metabolic indices predictive of ischemic heart disease risk than variation in the LDL$\mathrm{C} / \mathrm{HDL}-\mathrm{C}$ ratio. This may propose the possibility of using atherogenic index as an indicator for ischemic heart risk.

The current study indicates that increase in risky lipids and reduction of HDL-C were especially in AMI patients with low serum iron than AMI patients with normal or high serum iron or UA patients with low serum iron that is in agreement with other studies. The concentration of LDL-C was regarded as oxidative risk factors for ischemic heart diseases ${ }^{\mathbf{1 1 7}}$. In addition, in AMI patients, both interleukin 10 and HDL-cholesterol decreased which confirmed their protective roles in coronary artery disease $^{(55)}$. Controversy, Lee et al. $(2006)^{(\mathbf{1 8})}$ reported that serum TG and HDL-C were not change significantly in ischemic heart disease (IHD) patients with low, normal, or high serum iron, whereas LDL-C were increased in IHD patients with low serum iron, compared with the normal subjects. Collectively, we can propose that lipid profile is an important pathophysiological parameter associated with atherosclerotic inflammatory process take place in ischemic heart diseases.

In the existing work, a significant positive correlation between serum iron with cardio protective agents IGF-1 and HDL-C and a negative correlation with IL6, TNFa, cholesterol, LDL-C, triglyceride and atherogenic index was evident in AMI patients with high or low serum iron. Likewise, a positive correlation between serum iron with IGF-1 and HDL-C and negative correlation with TNF $\alpha$, IL-6, atherogenic index and LDL-C were manifested in this investigation among UA patients with low serum iron. However, UA patients with high serum iron exhibited only significant negative correlation between serum iron with inflammatory cytokines (TNF $\alpha$ and IL-6), triglyceride and atherogenic index. These proofed correlations in this study concur with other investigators ${ }^{(56 \& 18)}$. Besides, Tziakas et al., (2003) ${ }^{(55)}$ reported a strong positive correlation between Interleukin 10 (IL-10) and HDLcholesterol in AMI patients, which might be an indication of a common synergistic anti-atherogenic action of two molecules in coronary artery disease.

These findings may propose that AMI and UA patients with low serum irons were associated with less cardiac protection and more proinflammatory states and risky lipids as 
well as may have a higher cardiovascular risk. In addition, Maria-Chiara et al. (1997) ${ }^{(\mathbf{5 6})}$ found that low serum iron levels were associated with an increased risk of ischemic heart disease and all-cause mortality. Also, high serum iron in both AMI and UA patients appeared to be associated with increasing cardioprotection and reducing proinflammatory cytokines and risky lipids.

The association between low serum iron and risk of AMI and UA are supported by several observations. The role of reduced oxygenation due to decreasing hemoglobin and hematocrit on the myocardial performance has been proved, especially on the physiologic level, so that anemia is a known risk factor for ischemic heart disease ${ }^{(57)}$. When hemoglobin concentration is reduced to less than half the normal level, ventricular function is impaired, presumably because the coronary flow has approached its maximum ${ }^{(58)}$. Based on knowledge of the physiologic role of oxygen delivery to the myocardium, anemia may be a cause of more severe cardiovascular diseases as IHD, congestive heart failure, rhythm disturbance and higher mortality rate ${ }^{(59)}$.

Moreover, IHD patients with low serum iron appear to be associated with increased myocardial damage markers as lactic dehydrogenase and aspartate amino transferase suggesting that myocardial anaerobic metabolic activity may be higher in IHD patients with low iron ${ }^{(\mathbf{1 8})}$. Bilirubin, an antioxidant derived from biliverdin ${ }^{(\mathbf{6 0})}$ was significantly lower in the blood of IHD patients with low serum iron which suggest that bilirubin had a protective role in the cardiovascular events ${ }^{(61,62 \& 18)}$.

Iron is physiologically essential; contradictory, dietary intake of iron elevates LDL-C that was regarded as oxidative risk factor and decreases plasma antioxidant levels ${ }^{(17)}$. In addition, excess iron can be a toxic and lead to the formation of a cascade of free radicals and lipid peroxidation $(\mathbf{1 4 , 1 5 )}$ and accelerate the process of atherosclerosis ${ }^{\mathbf{( 1 6 )}}$. This effect may be due to the ease with which iron is reversibly oxidized and reduced and thus able to participate in the generation of numerous powerful oxidant species $^{(\mathbf{1 4})}$.

AMI patients with especially low serum iron incorporated in this study revealed significant increase the measured proinflammatory cytokines (IL-6, TNF- $\alpha$ ) as well as risky lipids and significant decrease cardioprotective, HDL-C and IGF-1 as comparable to that of AMI patients with normal or high serum iron and UA patients with low serum iron. Whereas in UA patients with low serum iron, trig lyceride significantly increased and cardiopotective agents (IGF-1 and HDL-C) decreased significantly in comparison with UA patients with normal or high iron. These outcomes are in agreement with previous reports of Maria et al., $1997^{(\mathbf{5 6})}$, Lee et al., (2006) ${ }^{(\mathbf{1 8 )}}$ and Shin-Da et al., $2006^{(63)}$ who found that IHD patients with low serum iron were associated with a proinflammatory state, such as increased TNF- $\alpha$, IL-6, and C- reactive protein and decreased cardiac protective factor, such as decreased IGF-I. 
Subsequently, low serum iron in AMI patients selected in this study induced more injurious effects than UA patients. These effects may be consistent because measured serum ion levels were much reduced in AMI $(50.9 \pm 4.8 \mathrm{mg} / \mathrm{dl})$ than UA patients $(52.12 \pm 5.6 \mathrm{mg} / \mathrm{dl})$ which produced more damaging effects. Beside, these effects may be reasoned to more damage in AMI, similar to chronic inflammatory diseases, may be accompanied by a significant decrease of iron and total iron binding capacity, especially during the first 3 days ${ }^{(64)}$. In addition, potential mechanisms include direct damage of the vessels or an immunologic inflammatory response were especially in AMI patients. An increased uptake of iron in the reticulo-endothelial system for synthesis of ferritin may account for the lowered $\mathrm{Fe}$ level and iron saturation of tranferrin and TIBC in cases of $\mathrm{AMI}^{(65,66)}$. Moreover, these findings could be the result of the intensity and the duration of the inflammatory stimulus, which characterize AMI, as well as perhaps being the consequence of the different patterns of immunological reactions and pathophysiological processes that underlie AMI cases.

\section{Conclusions:}

The outcomes of this study can be summarized as following: Both AMI and UA patients were associated with a pro-inflammatory state, such as increased TNF- $\alpha$ and IL-6, increased risky lipids (cholesterol, triglyceride, LDL-C, atherogenic index) and decreased cardiac protective factors, such as IGF-1 and HDL-C. These findings support the pivotal role of inflammation in pathophysiology of both patients' population as well as the protective role of IGF-1 in ischemic heart disease. In addition, low serum iron in both AMI and UA patients was associated with more pro inflammatory state and less cardiac protection than normal subjects or patients with either normal or high serum iron. However, the deleterious effects of low serum iron were more in AMI than UA patients. Also, a positive correlation was evident between serum iron and cardioprotective agents, IGF-1 and HDL-C with negative correlation with proinflammatory cytokines and risky lipids. The underlying mechanis ms of these effects are open for further investigations. Of course, further extensive studies are required to clarify the detailed mechanis m of low iron in heart diseases

\section{Clinical application:}

For clinical application, the low levels of serum iron adjoined with other cardiac risk factors might be used as a set of prognostic markers for predicting possible occurrence and recurrence of ischemic heart diseases or possible sudden death. We may further propose that IHD patients should regularly monitor their serum iron. In addition, strong therapeutic and preventive approaches of anemia and low serum iron might improve the outcome of IHD.

\section{REFERENCES}

1. Effat, M.A. Pathophysiology of ischemic heart disease: an overview, AACN Clin Issues 6 (1995), pp.369-374.

2. Koenig, W. Inflammation and coronary heart disease: an 
overview, Cardiol Rev 9 (2001), pp. 31-35.

3. Ferns G., Motani A. and Anggard E. The insulin-like growth factors: their putative role in atherogenesis. Artery. 18 (1991): pp.197-225.

4. Janssen J.A.M., Stolk R.P., Pols H.A.P. Serum total IGF-I, free IGF-I, and IGFBP-1 levels in an elderly population: relation to cardiovascular risk factors and disease. Arterioscler Thromb Vasc Biol 18 (1998), pp. 277282.

5. Ren J., Samson W.K. and Sowers J.R. Insulin-like growth factor I as a cardiac hormone physiological and pathophysiological implications in heart disease, J Mol Cell Cardiol 31 (1999), pp. 2049-2061.

6. Conti E., Andreotti F., Sciahbasi A., Riccardi P., Marra G., Menini E., Ghirlanda G. and Maseri A. Markedly reduced insulin-like growth factor-1 in the acute phase of myocardial infarction, $J \mathrm{Am}$ Coll Cardiol 38 (2001), pp. 2632.

7. Libby P. Inflammation in atherosclerosis. Nature $\mathbf{4 2 0}$ (2002), pp. 868-874.

8. Fuster V. and Lewis A. Mechanisms leading to myocardial infarction: insights from studies of vascular biology. Circulation 90 (1994), pp. 2126-2146.

9. Hansson G.K. Immune mechanis ms in atherosclerosis, Arterioscler Thromb Vasc Biol 21 (2001), pp. 18761890.
10. Ridker P.M., Rifai N. and Pfeffer M. et al., Elevation of tumour necrosis factor- $\alpha$ and increased risk of recurrent coronary events after myocardial infarction, Circulation 101 (2000), pp. 2149-2153.

11. Cesari M., Penninx B.W. and Newman A.B.. Inflammatory markers and onset of cardiovascular events: results from the Health ABC Study, Circulation 108 (2003), pp. 2317-2322.

12. Skoog T., Dichtl W. and Boquist S. et al., Plasma tumour necrosis factor- $\alpha$ and early carotid atherosclerosis in healthy middle-aged men, Eur Heart J 23 (2002), pp. 376-383

13. Hojo Y. and Shimada K. Role of cytokines in acute coronary syndrome, Nippon Rinsho $\mathbf{5 6}$ (1998), pp. 2500-2503.

14. Shah S.V. and Alam M.G. Role of iron in atherosclerosis, $\mathrm{Am} \mathrm{J}$ Kidney Dis 41 (2003), pp. S80 S83.

15. Reddy M.B. and Clark L. Iron, oxidative stress, and disease risk, Nutr Rev 62 (2004), pp. 120-124.

16. de Valk B. and Marx J.J. Iron, atherosclerosis, and ischemic heart disease, Arch Intern Med 159 (1999), pp. 1542-1548.

17. Pool G.F. and van Jaarsveld $H$. Dietary iron elevates LDLcholesterol and decreases plasma antioxidant levels: influence of antioxidants, Res Commun Mol Pathol Pharmacol 100 (1998), pp. 139-150.

18. Lee S.D., Chen L.M., Kuo W.W., Shu W.T., Kuo W.H., Huang E.J., Tsai C.C., Li P.C., 
Liu J.Y., Huang C.Y. Serum insulin-like growth factor-axis and matrix metallo-proteinases in patients with rheumatic arthritis or rheumatic heart disease. Clin Chim Acta. 367(1-2) (2006), pp.62-68.

19. Goodwin J.F. Direct estimation of serum iron and unsaturated iron binding capacity in a single aliquot. Clin Biochem. $\mathbf{3}$ (1970):307-14.

20. Flegg M.H. Quantitive enzymatic colorimetric estimation of total cholesteroland HDL cholesterol in serum or plasma. Ann Clin Biochem; 10, (1973), pp.79-85.

21. Finley P.R. Enzy matic determination of HDL cholesterol. Clin Biochem; 24 (1978), pp.931-934

22. Bucolo, and David $\mathbf{H}$. Quantitative determination of serum triglycerides by the use of enzy mes. Clin. Chem., 19 (1973), pp. 276-284.

23. Friedewald W.T., Levy R.I. and Fredericks on D.S. Estimation of the concentration of Low density lipoprotein cholesterol in plasma without the use of preoperative ultracentrifuge. Clin.Chem., $\mathbf{1 8}$ (1972),pp.499-504.

24. Grundy S.M., Greenland P.H., and Herd L.. Cardiovascular and risk factor evaluation of health American adult. Circulation, 75 (1987, pp. 2340A-2345.

25. Bennet A.M., van Maarlea M.C., Hallquistc J., Morgensterng R., Frostegår df J., Wi mand B., Princeb J.A. and de Fairea, e U. Association of TNF- $\alpha$ serum levels and TNFA promoter polymorphisms with risk of myocardial infarction. Atherosclerosis 187, (2006),pp. 408-414.

26. Mojgan Y., Ingrid R., Joop A., M.J., L., Omer T., Njajou A., H., Huibert A.P., Steven W. J. Lamberts, Jacqueline C.M. and Cornelia M.: An InsulinLike Growth Factor-I Promoter Polymorphis m Is Associated With Increased Mortality in Subjects With Myocardial Infarction in an Elderly Caucasian Population. American J. of cardiology 97(2006), pp.1274-1276.

27. Skoog T., Dichtl $W$. and Boquist S. Plasma tumour necrosis factor- $\alpha$ and early carotid atherosclerosis in healthy middle-aged men, Eur Heart $J 23$ (2002), pp. 376-383.

28. Cesari M., Penninx B.W. and Newman A.B. Inflammatory markers and onset of cardiovascular events: results from the Health ABC Study, Circulation 108 (2003), pp. 2317-2322.

29. Kai H., Ikeda $H$., Yasukawa $H$. et al., Peripheral blood of matrix metalloproteinases-2 and -9 are elevated in patients with acute coronary syndromes. $\mathrm{J}$ Am Coll Cardiol 32 (1998), pp. 368-372

30. Mallat Z., Corbaz A., Scoazec A. et al. Expression of interleukin-18 in human atherosclerotic plaques and relation to plaque instability. Circulation 104 (2001), pp. 1598-1603.

31. Haddy N., Sass C. and Droesch S. et al., IL-6, TNF- $\alpha$ and atherosclerosis risk indicators in a 
healthy family population: the Stanislas cohort, Atherosclerosis 170 (2003), p. 277.

32. Dandona P., Weinstock $R$. and Thusu K. et al., Tumour necrosis factor- $\alpha$ in sera of obese patients: fall with weight loss, $J$ Clin Endocrinol Metab 83 (1998), pp. 2907-2910.

33. Sethi J.K. and Hotamisligil G.S. The role of TNF- $\alpha$ in adipocyte metabolism, Semin Cell Dev Biol 10 (1999), pp. 19-29.

34. Biasucci L.M., Vitelli A., Liuzzo G. Elevated levels of interleukin6 in unstable angina. Circulation 94 (1996),pp. 874-877.

35. GABRIEL1 A.S., AHNVE2 S., WRETLIND3 B. and MARTINSSON1 A. IL-6 and IL-1 receptor antagonist in stable angina pectoris and relation of IL-6 to clinical findings in acute myocardial infarction. Journal of Internal Medicine 248 (2000),pp. 61-66.

36. P.C. Heinrich, J.V. Castell, T. Andus, Interleukin-6 and the acute phase response. Biochem $J$. 265 (1990), pp. 621-636.

37. Yamauchi-Takihara K., Ihara Y., Ogata A., Yoshizaki K., Azuma J., Kishimoto T. Hypoxic stress induces cardiac myocyte-derived interleu kin-6. Circulation 91(1995),pp. 152024.

38. Rus H.G., Vlaicu R., Niculescu F. Interleukin-6 and interleukin8 protein and gene expression in human arterial atherosclerotic wall. Atherosclerosis; 127 (1996),pp. 263-71.

39. Miyao Y., Yasue H., Ogawa $H$. Elevated plasma interleukin-6 levels in patients with acute myocardial infarction. Am Heart J. 126 (1993),pp. 1299304.

40. Juul A., Scheike T., Davidsen M. Low Serum Insulin-Like Growth Factor -I Is Associated With Increased Risk of Ischemic Heart Disease. Circulation. 106 (2002), pp.939-945.

41. Matthews K.G., Devlinb G.P., Stuarta S.P., Conaglenb J.V. and Bass J.J. Cardiac IGF -I manipulation by growth hormone following myocardial infarction. Growth Hormone andIGF-1 Research, 14 (2004), pp. 251260.

42. Ruotolo G., Båvenholm P., Brismar K., Eféndic S., Ericsson C., de-Faire U., Nilsson $J$. and Hamsten A., Serum insulin-like growth factorI level is independently associated with coronary artery disease progression in young male survivors of myocardial infarction: beneficial effects of bezafibrate treatment. Journal of the American College of Cardiology, 35, (2000),pp. 647654.

43. Hong N.L., Pedersen K., Brismar K., Hall U. and de Faire U. Quantitative genetic analyses of insulin-like growth factor I (IGF-I), IGF-binding protein-1, and insulin levels in middle-aged and elderly twins, $J$ Clin Endocrinol Metab $\mathbf{8 1}$ (1996), pp. 1791-1797.

44. Vaessen N., Heutink P., Janssen J.A., Witteman J.C., Testers L., Hofman A., Lamberts S.W., Oostra B.A., Pols H.A. and van 
Duijn C.M., A polymorphism in the gene for IGF-I functional properties and risk for type 2 diabetes and myocardial infarction, Diabetes 50 (2001), pp. 637-642.

45. Li B., Setoguchi M., Wang X., Andreoli A.M., Leri A., Malhotra A., Kajstura J. and Anversa P. Insulin-like growth factor-1 attenuates the detrimental impact of nonocclusive coronary artery constriction on the heart, Circ Res 84 (1999), pp. 1007-1019.

46. Jeppesen J., Ole Hein H., Suadicani P., Gyntelberg F. Relation of High TG-Low HDL Cholesterol and LDL Cholesterol to the Incidence of Ischemic Heart Disease. Arteriosclerosis, Thrombosis, and Vascular Biology. 17 (1997),pp.1114-1120.

47. Hopkins P.N., Lily L., Hunt S.C. and Brinton E.A. Plas ma triglycerides and type III hyperlipidemia are independently associated with premature familial coronary artery disease. $J$ Am Coll Cardiol, 45 (2005), pp.1003-1012.

48. Nadeem N., Danesh J., Eiriks dottir G., Sigurdss on G., Wareham N., Bingham S., Boekhol dt S.M., Khaw K, Gudnason V. Triglycerides and the Risk of Coronary Heart Disease. Circulation. 115 (2007), pp.450-458.

49. Austin M.A., Breslow J.L., Hennekens C.H., Buring J.E., Willett W.S., Krauss R.M. Low-density lipoprotein subclass patterns and risk of myocardial infarction. JAMA.260 (1988), pp.1917-1922.

50. Karpe F., Steiner G., Uffelman K., Olivecrona T., Hamsten A. Postprandial lipoproteins and progression of coronary atherosclerosis. Atherosclerosis.106 (1994), pp.83-97.

51. Hamsten A., Wi man B., Defaire U., Blombäck $\mathbf{M}$, Increased plasma level of a rapid inhibitor of tissue plasminogen activator in young survivors of myocardial infarction. $N$ Engl $J$ Med. 313 (1985),pp.1557-1563.

52. Mehta J., Mehta P., D. Laws on, Saldeen T.. Plasma tissue plasminogen activator inhibitor levels in coronary artery disease: correlation with age and serum triglyceride concentrations. J Am Coll Cardiol. 9 (1987),pp.263-268.

53. Moor E., Silveira A., Van't Hooft F., Suontaka A.M., Eriksson P., Blombäck M., Hamsten A. Coagulation factor VII mass and activity in young men with myocardial infarction at a young age. Arterioscler Thromb Vasc Biol. 15 (1995),pp.655-664.

54. Lemieux I., Lamarche B., Couillard C., Pascot A., Cantin B., Bergeron J., Dagenais G. R., Despr J. Total Cholesterol/HDL Cholesterol Ratio vs LDL Cholesterol/HDL Cholesterol Ratio as Indices of Ischemic Heart Disease Risk in Men. Arch Intern Med. 161 (2001), pp.26852692 .

55. Tziakas D.N., Georgios K.C., Helen I.H., John T.P., Elias D.P., Grigorios A.T., Evropi P., Ioannis K.T., S pilios M.K. and 


\begin{abstract}
Dimitrios I.H. Antiinflammatory cytokine profile in acute coronary syndromes: behavior of interleukin-10 in association with serum metalloproteinases and proinflammatory cytokines. International Journal of Cardiology 92, (2003), pp. 169-175.
\end{abstract}

56. Maria-Chiara C., Jack M.J., Marcel E.S., Luigi F., Marco P., Robert B.W. and Charles H.H., Serum Iron Level, Coronary Artery Disease, and All-Cause Mortality in Older Men and Women. American J. of cardiology 79 (1997),pp. 120127.

57. Shulman L.N., Braunwald E., Rosenthal D.S., Hematologicaloncological disorders and heart disease. In: Braunwald E. Heart Disease: A Textbook of Cardiovascular Medicine. 5th edn. Phildadelphia: WB Saunders, (1997), pp.1786- 808.

58. Florezano F., Diaz G., Regonesi C., Escobar E., Left ventricular function in chronic anemia: evidence of noncathecholamine positive inotropic factor in the serum. Am J Cardiol 54, (1984), pp.638-45.

59. Zeidman A., Fradin Z., Blecher A., Oster H.S., Avrahami Y., Mittelman M., Anemia as a risk factor for ischemic heart disease. ISR Med Assoc. 6. (2004).pp.1618.

60. McGeary R.P., Szyczew A.J. and Toth I., Biological properties and therapeutic potential of bilirubin, Mini Rev Med Chem 3 (2003), pp. 253256.

61. Mayer M. Association of serum bilirubin concentration with risk of coronary artery disease, Clin Chem 46 (2000), pp. 1723-1727.

62. Greabu M., Olinescu R., Kummerow F.A. and Crocnan D.O. The levels of bilirubin may be related to an inflammatory condition in patients with coronary heart disease, Acta Pol Pharm 58 (2001), pp. 225-231.

63. Shin-Da L., Chih-Yang H., Wen-Tong S., Ter-Hsin C., Chung-Sheng L., Chung-Jung L., Wei-Wen $K$. and Li-Mien C., Pro-inflammatory states and IGF-I level in ischemic heart disease with low or high serum iron. Clinica Chimica Acta 370, (2006),pp. 50-56.

64. Fitzsimons E.J., Kaplan K., Rapid drop in serum iron concentration in myocardial infarction. Am J Clin Pathol .73 (1980), pp.:552-5.

65. Van der Schouw Y.T., van der Veeken P.M., Kok F.J., Koster J.F., Schouten E.G., Hofman A. Iron status in the acute phase and six weeks after myocardial infarction. Free Radic Biol Med. 8 (1990), pp.47-53.

66. Magnusson M.K., Sigfusson N., Sigvak das on H., Johanness on G.M., Magnusson S., Thorgeirsson G. Low ironbinding capacity as a risk factor for myocardial infarction. Circulation 89 (1994), pp.102-8. 


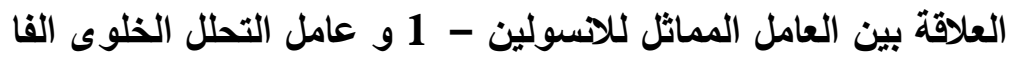

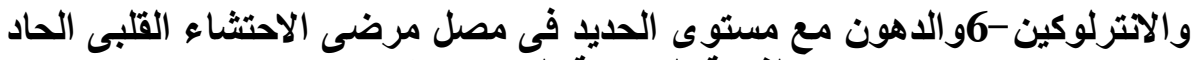

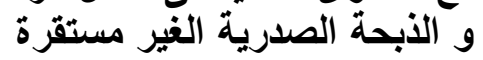

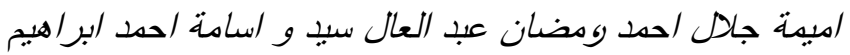

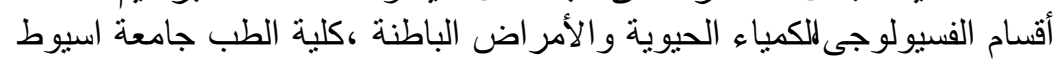

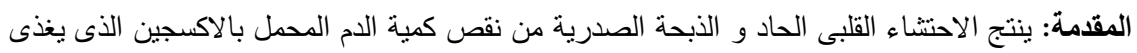

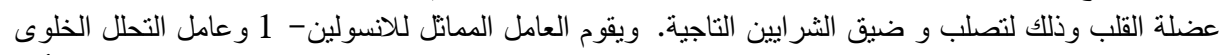

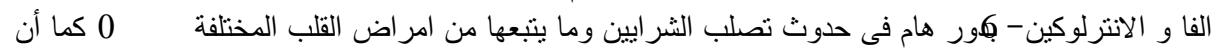

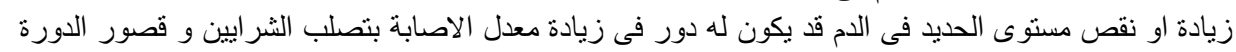
الدموية التاجية

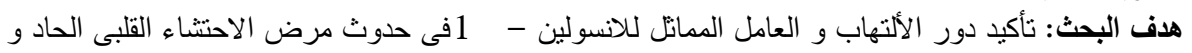

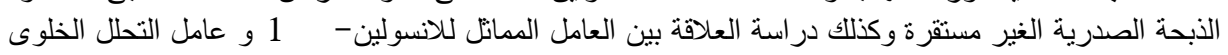

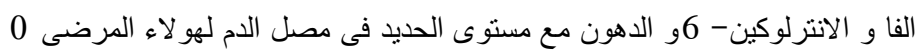

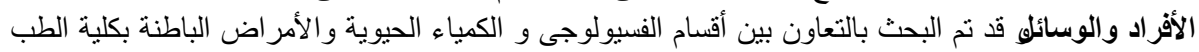

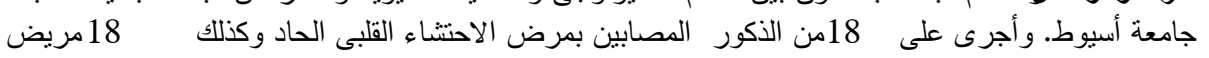

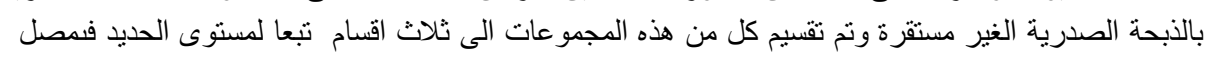

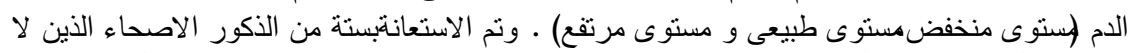

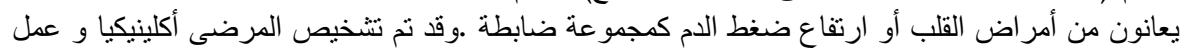

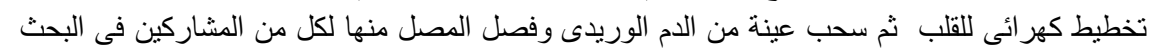

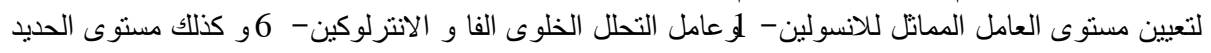

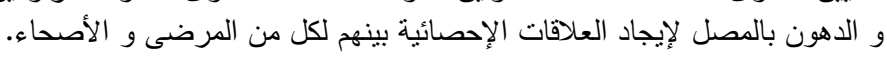

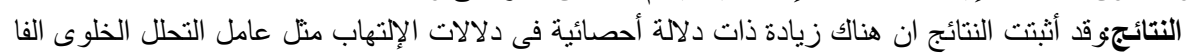

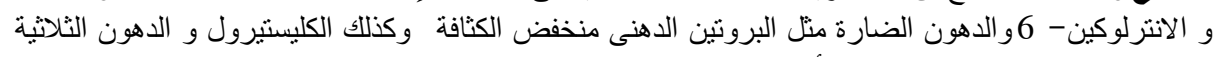

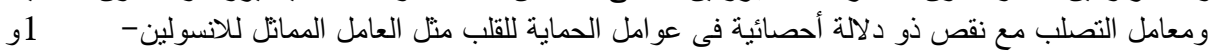

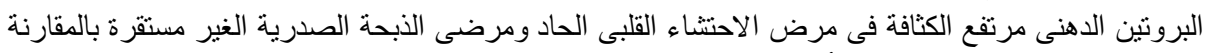

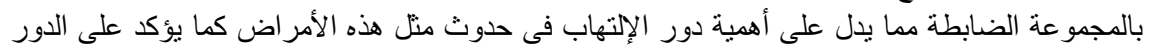

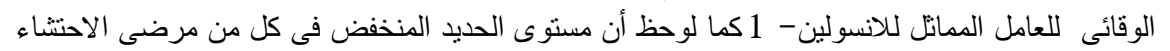

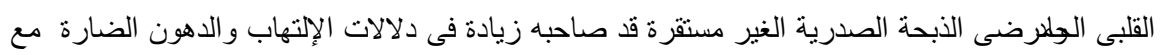

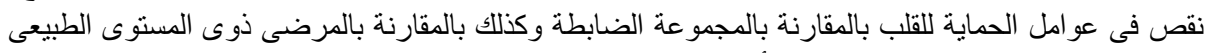

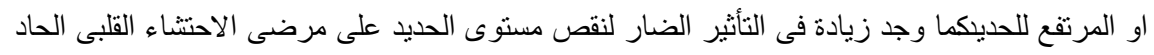
عنه فى مرضى الذبحة الصدرية الغير مستقرة.

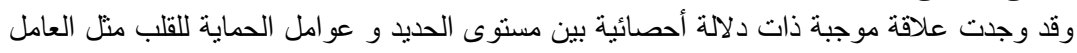

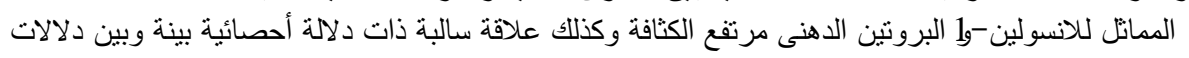

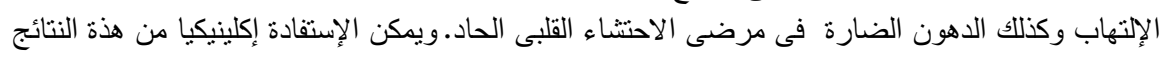

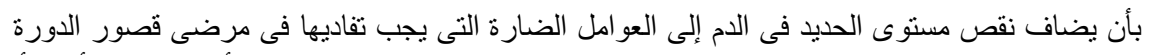

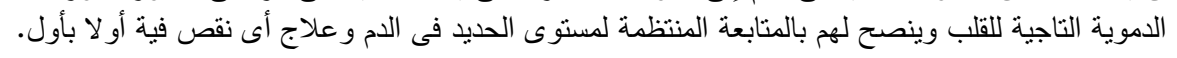

